\title{
UPAYA MENINGKATKAN KEMAMPUAN MEMAHAMI CERITA PADA MATERI CERITA ANAK PADA MATA PELAJARAN BAHASA INDONESIA MENGGUNAKAN STRATEGI WHAT MY LINE SISWA KELAS VII.1 SMPN 21 KOTA PEKANBARU
}

\author{
Alfa Yendri \\ SMP Negeri 21 Pekanbaru \\ e-mail: alfayendri@yahoo.com
}

\begin{abstract}
This study aims to determine the effort to improve the ability to understand the story on children's story materials on Indonesian subjects using what my line strategy students VII.1 SMPN 21 Kota Pekanbaru. This study was conducted in two cycles and each cycle was done in two meetings. In order for this classroom action research to work well without the obstacles that interfere with the smoothness of the research, the researchers arrange the steps passed in classroom action research, namely: 1) Planning / preparation of action, 2) Implementation of action, 3) Observation, and Reflection. Based on the results of the research, it can be seen that the occurrence of an increase in the ability to understand the story of children in the subject matter of children in the field of Indonesian studies. In the first cycle student learning outcomes are categorized by the average classical value of 80 . While in cycle II there is an increase in the ability to understand the story of children with high category with average classical value 91 thereby the use of what my line strategy can improve the ability to understand the story of children on the material stories of children in the field of study of Indonesian students of class VII in SMPN 21 Pekanbaru City on Indonesian lessons.
\end{abstract}

Keywords—ability to understand, child story, what my line

\section{Abstrak}

Penelitian ini bertujuan untuk mengetahui upaya meningkatkan kemampuan memahami cerita pada materi cerita anak pada mata pelajaran Bahasa Indonesia menggunakan strategi what my line siswa kelas VII.1 SMPN 21 Kota Pekanbaru. Penelitian ini dilakukan dalam dua siklus dan tiap siklus dilakukan dalam dua kali pertemuan. Agar penelitian tindakan kelas ini berhasil dengan baik tanpa hambatan yang mengganggu kelancaran penelitian, peneliti menyusun tahapan-tahapan yang dilalui dalam penelitian tindakan kelas, yaitu: 1) Perencanaan/persiapan tindakan, 2) Pelaksanaan tindakan, 3) Observasi, dan Refleksi. Berdasarkan hasil penelitian, maka dapat diketahui bahwa terjadinya peningkatan kemampuan memahami cerita anak pada materi cerita anak bidang studi Bahasa Indonesia. Pada siklus I hasil belajar siswa dikategorikan dengan rata-rata klasikal nilai 80. Sedangkan pada siklus II terjadi peningkatan kemampuan memahami cerita anak dengan kategori tinggi dengan rata-rata klasikal nilai 91 dengan demikian penggunaan strategi what my line dapat meningkatkan kemampuan memahami cerita anak pada materi cerita anak bidang studi Bahasa Indonesia siswa kelas VII di SMPN 21 Kota Pekanbaru pada pelajaran Bahasa Indonesia.

Kata kunci-kemampuan memahami, cerita anak, what my line

\section{PENDAHULUAN}

Bahasa merupakan sarana untuk saling berkomunikasi, saling berbagi pengalaman, saling belajar dari yang lain dan untuk meningkatkan kemampuan intelektual. Hal ini berarti bahwa bahasa memiliki peran yang penting bagi manusia. Dengan demikian, dapat dimaklumi jika di sekolah terdapat mata pelajaran bahasa, khususnya bahasa Indonesia. 
Mata pelajaran bahasa Indonesia merupakan salah satu sarana yang dapat mengakses berbagai informasi dan kemajuan tersebut. Untuk itu, kemahiran berkomunikasi dalam Bahasa Indonesia secara lisan dan tertulis harus benar-benar dimiliki dan ditingkatkan. Oleh sebab itu, seorang guru dituntut untuk mampu mencapai kompetensi dasar yang sudah ditetapkan.

Selanjutnya Zaenal Arifin mengatakan bahwa Bahasa Indonesia yang kedudukannya sebagai Bahasa Nasional berfungsi sebagai lambang identitas nasional, alat perhubungan antar warga, antar daerah, dan antar budaya, dan alat yang memungkinkan penyatuan berbagai-bagai suku bangsa dengan latar belakang sosial budaya dan bahasanya masing-masing ke dalam kesatuan kebangsaan Indonesia. Sebagai lambang kebanggaan kebangsaan, bahasa Indonesia mencerminkan nilai-nilai sosial budaya yang mendasari rasa kebangsaan kita. Atas dasar kebanggaan ini, bahasa Indonesia kita pelihara dan kita kembangkan serta rasa kebanggaan pemakainya senantiasa kita bina. ${ }^{1}$

Pembelajaran bahasa Indonesia di sekolah diarahkan untuk meningkatkan kemampuan siswa dalam berkomunikasi dengan bahasa Indonesia baik secara lisan maupun tertulis. Untuk mewujudkannya maka pelajaran bahasa Indonesia diprogramkan untuk mengembangkan pengetahuan, sikap positif terhadap bahasa Indonesia dan ketrampilan berbahasa. Adapun ketrampilan berbahasa dalam kurikulum terdiri atas empat aspek, yaitu ketrampilan menyimak, ketrampilan berbicara, ketrampilan membaca dan ketrampilan menulis. Setiap keterampilan itu erat sekali berhubungan dengan tiga ketrampilan lainnya dengan cara yang beraneka ragam. Dalam memperoleh ketrampilan berbahasa, biasanya melalui suatu hubungan urutan yang teratur: mulamula pada masa kecil kita belajar menyimak bahasa, kemudian berbicara, sesudah itu belajar membaca dan menulis. Menyimak dan berbicara dipelajari sebelum memasuki sekolah. Keempat ketrampilan tersebut pada dasarnya merupakan satu kesatuan, merupakan catur tunggal. ${ }^{2}$

Hampir setiap guru Bahasa Indonesia setuju akan pentingnya pemahaman anak dalam memahami cerita. Semua siswa yang berada di dalam kelas, ter kecuali yang memang secara alami sudah bisa memahami, perlu diberi rangsangan melalui teknik dan cara pengajaran yang tepat agar mampu memahami cerita dengan baik. Anak-anak akan belajar secara efektif jika mereka sudah memahami pelajaran dengan baik. Dari penjelasan diatas, diketahui bahwa pemahaman dalam memahami cerita sangat dibutuhkan oleh siswa. Bagaimana mungkin anak akan memperoleh hasil belajar yang baik, jika ia tidak memiliki pemahaman yang baik.

Permasalahan yang berkenaan dengan siswa di kelas, jika tidak dicari solusi dan dibiarkan berlalu begitu saja, akan lebih kompleks dan berlarut-larut. Akibatnya, akan dirasakan pada ketidak-kompetenan siswa di masyarakat yang berhubungan dengan materi pelajaran. Permasalahan siswa maupun guru selama proses belajar, menjadi prioritas, untuk secepatnya diteliti penyebab dan solusinya. Hal itu perlu dipahami oleh seorang guru, karena keberhasilan belajar siswa ditentukan, sejauh mana guru memiliki inisiatif perbaikan terhadap prosedur dan hal yang berkaitan dengan proses yang telah dilakukan.

Untuk itu kemampuan guru sangat dituntut dalam mengelola kelas agar suasana belajar siswa selalu aktif dan produktif melalui strategi dan metode mengajar yang direncanakan. Mengajar itu sendiri juga merupakan serangkaian peristiwa yang dirancang oleh guru dalam memberi dorongan kepada siswa belajar, baik yang bersifat individual, maupun kelompok. Rangkaian peristiwa dalam mengajar, sebagai pendorong siswa belajar diterima oleh siswa secara individual pula. Artinya, setiap individu siswa memperolah pengaruh dari luar dalam proses belajar dengan kadar yang berbeda-beda. Sesuai dangan kemampuan potensial rnasing-masing. Oleh karena itu hasil belajar pun akan berbeda-beda pula.

Di dunia pendidikan umumnya dan di sekolah pada khususnya cerita anak mendapat tempat tersendiri. Pada mata pelajaran Bahasa Indonesia cerita anak dapat digunakan sebagai salah satu media yang digunakan untuk melatih anak dalam kemampuan berbahasa. Hal ini dilakukan untuk mengasah kemampuan anak baik menulis, membaca, berbicara maupun menyimak.

\footnotetext{
${ }^{1}$ Zaenal Arifin, Cermat Berbahasa Indonesia untuk Perguruan Tinggi, (Jakarta: CV. Akademika Pressindo, 2006), hlm.12

2 Tarigan Henry, G. Berbicara Sebagai Suatu Keterampilan Berbahasa. (Bandung: Angkasa, 1998), hlm. 1
} 
Cerita anak-anak merupakan media seni yang mempunyai ciri-ciri tersendiri sesuai dengan selera penikmatnya. Tidak seorang pengarang cerita anak-anak yang mengabaikan dunia anakanak. Dunia anak-anak tidak dapat diremehkan dalam proses keaktifannya. Maka dari itu, cerita anak-anak dicipta oleh orang dewasa seolah-olah merupakan ekspresi diri anak-anak lewat idiomidiom bahasa anak-anak. Motif dalam suatu cerita anak merupakan unsur yang menonjol. Unsurunsur ini berupa benda, binatang yang mempunyai kekuatan gaib, konsep perbuatan, tokoh atau sifat tertentu.

Berdasarkan hasil wawancara dengan guru dan siswa mengenai pembelajaran memahami cerita, terdapat faktor-faktor yang menyebabkan rendahnya kegiatan memahami cerita. Dalam kenyataan yang terjadi di kelas, guru menghadapi anak yang sulit memahami materi pelajaran, meskipun guru sudah berupaya sebaik mungkin dalam menjelaskan materi, tetapi sebagian anak masih belum memahami apa yang telah dijelaskan. Selain itu, lingkungan sangat mempengaruhi diri siswa misalnya lingkungan di luar sekolah yang kurang memotivasi siswa dalam belajar. Sedangkan kendala guru misalnya belum menggunakan secara efektif untuk strategi pembelajaran memahami. Dari beberapa permasalahan tersebut membuktikan bahwa kemampuan memahami siswa masih rendah.

Berdasarkan hasil pengamatan selama peneliti bertugas di SMPN 21 Kota Pekanbaru ditemui gejala-gejala atau fenomena khususnya pada aspek kemampuan memahami cerita yaitu, sebagai berikut:

1. Kemampuan memahami cerita yang diperoleh siswa belum optimal, hal ini dilihat dari hasil penilaian terhadap kemampuan memahami cerita siswa, kemampuan siswa masih mencapai rata-rata 67,3 atau dibawah nilai KKM yang sudah ditetapkan yaitu 75 .

2. Rendahnya kemampuan siswa dalam memahami cerita. Dilihat dari nilai rata-rata siswa yang dapat memahami cerita dengan baik hanya sedikit, sedangkan sisanya belum dapat memahami cerita dengan baik.

3. Kurangnya pemahaman siswa dalam memahami isi cerita sehingga tidak mampu menyimpulkan isi cerita dengan baik.

4. Siswa kesulitan dalam memahami unsur-unsur cerita dan kurang keinginannya untuk bertanya pada guru.

5. Sebahagian siswa hanya terdiam bila disuruh menceritakan cerita yang telah dibacakan oleh temannya.

Dari fenomena-fenomena atau gejala-gejala tersebut di atas, terlihat rendahnya kemampuan siswa dalam memahami cerita. Keadaan ini menurut analisis penulis dipengaruhi oleh cara guru mengajar yang kurang sesuai dengan materi yang diajarkan. Guru cenderung menyampaikan materi dengan ceramah atau pun hanya dengan memberikan tugas kepada siswa sehingga siswa menjadi pasif. Dengan kata lain interaksi antara guru dan siswa cenderung satu arah yaitu dan guru ke siswa.

Usaha yang di lakukan oleh guru untuk meningkatkan kemampuan siswa dalam memahami cerita adalah dengan strategi pembelajaran What My Line. Alasan pemilihan strategi ini adalah kemudahan yang diberikan kepada siswa dengan membantu para siswa mempelajari materi kognitif. Oleh sebab itu, peneliti tertarik ingin melakukan suatu penelitian tindakan dengan judul "Upaya Meningkatan Kemampuan Memahami Cerita Pada Materi Cerita Anak Pada Mata Pelajaran Bahasa Indonesia Menggunakan Strategi What My Line Siswa Kelas VII.1.1 SMPN 21 Kota Pekanbaru".

\section{METODE}

\section{A. Subjek dan Objek Penelitian}

Sebagai subjek dalam penelitian ini adalah siswa kelas VII.1 tahun pelajaran 2016/2017 dengan jumlah siswa sebanyak 43 orang. Sedangkan menjadi objek penelitian ini adalah penggunaan strategi what my line dan kemampuan memahami cerita siswa kelas VII.1 SMPN 21 
Kota Pekanbaru. Kemudian penelitian ini terdiri dari dua variabel yaitu penerapan strategi what my line (Variabel X), kemampuan memahami cerita (Variabel Y).

\section{B. Tempat Dan Waktu Penelitan}

Penelitian tindakan kelas ini dilaksanakan di kelas VII.1 SMPN 21 Kota Pekanbaru.Waktu penelitian dilakukan pada semester ganjil tahun ajaran 2016/2017 tepatnya pada bulan September 2016

Menentukan jumlah klasifikasi yang diinginkan, yaitu 4 klasifikasi yaitu sangat tinggi, tinggi, rendah, dan rendah sekali. Karena jumlah siswa 16 orang maka sekor maksimal $1376(43 x$ $4 \times 8)$ dan skor minimal $344(43 \times 1 \times 8)$.

a. Interval (I), yaitu: $I=\frac{\text { Skor max }- \text { Skor min }}{4}=\frac{1376-344}{4}=256$

b. Menentukan tabel klasifikasi standar pelaksanaan Strategi What My Line, yaitu:

$\begin{array}{lccc}\text { Sangat Tinggi } & 1119 & - & 1376 \\ \text { Tinggi } & 861 & - & 1118 \\ \text { Rendah } & 603 & - & 860 \\ \text { Sangat Rendah } & 344 & - & 602\end{array}$

Adapun aktivitas siswa yang di lihat dalam penerapan Strategi What My Line adalah sebagai berikut :

1) Siswa segera membentuk kelompok.

2) Siswa memperhatikan guru dalam menulis tentang materi yang dipelajari pada potonganpotongan kertas terpisah.

3) Siswa memilih satu potongan kertas yang ada dalam kotak.

4) Siswa mengerjakan tugas.

5) Siswa menyajikan hasil tugasnya didepan kelas.

6) Siswa membuat satu panel dari kelompok-kelompok lain.

7) Siswa memulai permainan dengan meminta tamu misteri untuk menyebutkan kategorinya siswa bergiliran menanyakan pertanyaan sampai bisa mengidentifikasi tamu tersebut.

8) Siswa yang belum menyampaiakan tamu-tamu misterinya, segera membuat suatu panel baru untuk tiap-tiap tamu.

\section{HASIL DAN PEMBAHASAN}

Berdasarkan hasil observasi pada gejala awal Kemampuan Memahami Cerita siswa diperoleh rata-rata persentase 67.3 dengan kategori rendah. Kemudian berdasarkam hasil observasi pada siklus pertama yang menunjukkan bahwa tingkat Kemampuan memahami cerita siswa mencapai dengan rata-rata klasikal 79, dengan kategori sedang. Sedangkan pada siklus II terjadi peningkatan mencapai kemampuan memahami cerita siswa diperoleh rata-rata persentase 91 dengan kategori tinggi.

Perbandingan antara Kemampuan memahami cerita siswa pada data awal, Siklus I dan Siklus II secara jelas dapat dilihat pada tabel berikut ini: 
Tabel 1.

Rekapitulasi Hasil Tes Kemampuan Memahami Cerita Siswa Pada Data Awal, Siklus I dan Siklus II

\begin{tabular}{|c|c|c|c|c|c|}
\hline \multirow{2}{*}{ No } & \multirow{2}{*}{ Nama Siswa } & \multicolumn{4}{|c|}{ Nilai Akhir } \\
\hline & & Data Awal & Siklus I & Siklus II & Keterangan \\
\hline 1 & AHMAD KARIM & 66 & 78 & 90 & Meningkat \\
\hline 2 & ANGGA NASRUDIN & 69 & 75 & 90 & Tetap \\
\hline 3 & APRILISANIA DWI KARTIKA & 71 & 90 & 93 & Tetap \\
\hline 4 & AULIA NADIA PUTRI & 66 & 79 & 95 & Tetap \\
\hline 5 & BRYAN HISKIA & 74 & 83 & 85 & Tetap \\
\hline 6 & CHINDY WALETA.D & 66 & 86 & 90 & Tetap \\
\hline 7 & CUT KIRAN HAWARI & 69 & 74 & 90 & Tetap \\
\hline 8 & CINDY ANGGRAINI & 70 & 78 & 93 & Tetap \\
\hline 9 & DIPO OKTAVIAN & 66 & 85 & 95 & Tetap \\
\hline 10 & ERIC ARDIANSYAH & 66 & 76 & 85 & Tetap \\
\hline 11 & FADHILLAH YUVINDRA & 69 & 76 & 90 & Tetap \\
\hline 12 & FADILA & 74 & 75 & 93 & Tetap \\
\hline 13 & FANIA WULANDARI & 74 & 76 & 93 & Tetap \\
\hline 14 & FERNANDO AJI SAPUTRA & 66 & 75 & 90 & Tetap \\
\hline 15 & GILAR WICAKSONO & 69 & 75 & 90 & Meningkat \\
\hline 16 & HAFIZ ADI WIRANATA & 74 & 90 & 93 & Meningkat \\
\hline 17 & IBNU AFDAL & 60 & 79 & 95 & Meningkat \\
\hline 18 & LUTFI AKBAR & 60 & 83 & 85 & Meningkat \\
\hline 19 & M.RAYHAN & 66 & 86 & 90 & Meningkat \\
\hline 20 & MAHARANI & 66 & 74 & 93 & Meningkat \\
\hline 21 & MIKE SEPTIAN TITO & 69 & 78 & 93 & Meningkat \\
\hline 22 & M.HIDAYATULLAH & 60 & 85 & 90 & Meningkat \\
\hline 23 & M.RIZKI & 60 & 76 & 90 & Meningkat \\
\hline 24 & M.RIZKI DWI.K & 73 & 76 & 90 & Meningkat \\
\hline 25 & M.ZAKI & 71 & 75 & 88 & Meningkat \\
\hline 26 & MUTIA ANGELINA SIAHAN & 60 & 90 & 93 & Meningkat \\
\hline 27 & NADILA ELVIRA HIDAYAT & 74 & 79 & 90 & Meningkat \\
\hline 28 & NAURA NAILA ADHINDA & 60 & 78 & 93 & Meningkat \\
\hline 29 & NOVIA SYAFITRI & 69 & 75 & 93 & Meningkat \\
\hline 30 & RAHMA NADIA MAHARANI & 74 & 76 & 94 & Meningkat \\
\hline 31 & RAHMAD UMBARI ENDAH & 60 & 79 & 90 & Meningkat \\
\hline 32 & RATNA SUCI ILMI NISA & 60 & 79 & 93 & Meningkat \\
\hline 33 & RAMONA DIXCI & 61 & 78 & 95 & Meningkat \\
\hline 34 & RESTU ARNAS PERMANA & 66 & 75 & 85 & Meningkat \\
\hline 35 & RIFKA RINABILA & 71 & 79 & 90 & Meningkat \\
\hline 36 & RISKA HARAHAP & 60 & 83 & 88 & Meningkat \\
\hline 37 & SAJID ALFARIZI & 66 & 86 & 93 & Meningkat \\
\hline 38 & SALSABILA NOVIANTI & 69 & 74 & 90 & Meningkat \\
\hline 39 & SHANAZWA DWI REVA & 74 & 78 & 90 & Meningkat \\
\hline 40 & SYIFA PUTRI NABILA & 73 & 90 & 93 & Meningkat \\
\hline 41 & TOMI ALFARIZI & 71 & 85 & 93 & Meningkat \\
\hline 42 & VERY FADLY & 60 & 76 & 90 & Meningkat \\
\hline 43 & YEHEZKIEL & 71 & 76 & 93 & Meningkat \\
\hline & Rata-rata & 67 & 79 & 91 & Meningkat \\
\hline
\end{tabular}

Sumber: Data Olahan Penelitian, Tahun 2016

Perbandingan tingkat Kemampuan memahami cerita siswa pada sebelum tindakan, siklus satu dengan kemudian siklus dua juga dapat dilihat pada gambar grafik garis berikut ini:

\section{Gambar 1. Histogram Kemampuan Memahami Cerita Individual Siswa} Pada Sebelum Tindakan, Siklus I dan Siklus II

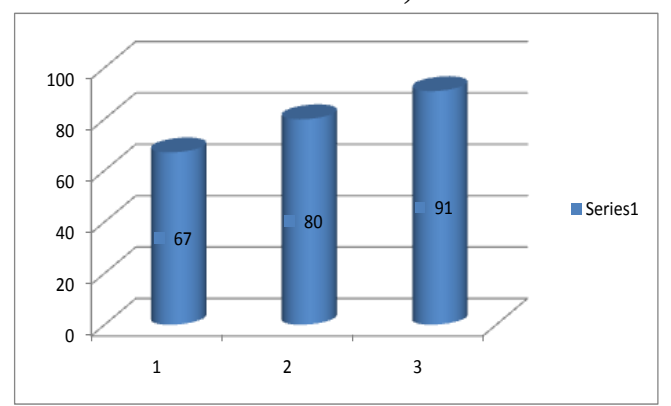

Sumber: Data Olahan Penelitian, Tahun 2016

Berdasarkan gambar histogram di atas dapat diketahui peningkatan kemampuan memahami cerita siswa sebelum tindakan diperoleh rata-rata persentase secara klasikal 67.3, terjadi peningkatan pada siklus I menjadi $80 \%$. Sedangkan peningkatan juga terjadi pada siklus II dengan rata-rata persentase secara klasikal 91. 


\section{KESIMPULAN}

Hasil pembahasan dan analisis bab IV dapat disimpulkan bahwa melalui Strategi What My Line dapat meningkatkan kemampuan memahami cerita pada pelajaran Bahasa Indonesia siswa kelas VII.1 SMPN 21 Kota Pekanbaru. Berdasarkan hasil penelitian diketahui bahwa Kemampuan Memahami Cerita siswa sebelum tindakan diperoleh rata-rata klasikal 67.3, pada siklus I terjadi peningkatan 79, sedangkan pada siklus II terjadi peningkatan dengan rata-rata klasikal 91. Keberhasilan ini disebabkan oleh penggunaan Strategi What My Line, sehingga Aktivitas siswa menjadi lebih meningkat. Pemahaman siswa akan meningkat dan pada gilirannya dapat meningkatkan kemampuan memahami cerita siswa.

\section{SARAN}

Bertolak dari kesimpulan dan pembahasan hasil penelitian, berkaitan dengan Strategi What My Line yang telah dilaksanakan, peneliti mengajukan beberapa saran, yaitu:

1. Agar penerapan Strategi What My Line tersebut dapat berjalan dengan baik, maka sebaiknya guru lebih sering menerapkannya dalam proses pembelajaran, khususnya pada materi memahami cerita.

2. Guru perlu melakukan upaya pada proses pembelajaran untuk mempertahankan Kemampuan Memahami Cerita siswa demi tercapainya hasil belajar yang optimal.

\section{DAFTAR PUSTAKA}

[1] Abdul Razak. Bahasa Indonesia Versi Perguruan Tinggi. Pekanbaru: Autografika, 2003.

[2] Arikunto, Penelitian Tindakan Kelas, Rineka Cipta: Jakarta, 2008.

[3] Burhan Nurgiyantoro, Pengantar Pemahaman Dunia Anak, Jakarta, 2007.

[4] Depdikbud. Kamus Besar Bahasa Indonesia, Balai Pustaka, Jakarta, 2002 Farida Rahim. Pengajaran Membaca di Sekolah Dasar. Jakarta: Bumi, 2007 Gimin. Instrumen dan Pelaporan Hasil Dalam Penelitian Tindakan Kelas. Pekanbaru: 2008.

[5] Mel Silberman, Active Learning, Yogyakarta: Yapendis, 2002.

[6] Santosa. Puji dkk “Materi dan Pembelajaran Bahasa Indonesia SD” Jakarta: UT, 2005.

[7] Sarumpaet, Riris K. Toha, Sastra Masuk Sekolah, Magelang: Indonesiatera, 2002.

[8] Slamet. Dasar-dasar Pembelajaran Bahasa dan Sastra Indonesia di Sekolah dasar. Surakarta: UNS Press, 2007.

[9] Sriyadi Dwijo, dkk, Buku Ajar Acuan Pengayaan, Jakarta: CV. Sindunata, 2006.

[10] Suharsimi Arikunto. Prosedur Penelitian Suatu Pendekatan Praktek. Jakarta: PT. Rineka Cipta, 1998.

[11] Suwardi Endraswara, Metode Penelitian Psikologi Sastra, Jakarta, 2002.

[12] Tarigan, Henry, G. Berbicara Sebagai Suatu Keterampilan Berbahasa. Bandung: Angkasa, 1998.

[13] Zaenal Arifin, Cermat Berbahasa Indonesia untuk Perguruan Tinggi, (Jakarta: CV. Akademika Pressindo, 2006). 